\title{
La sidérurgie ancienne en Lorraine
}

Marc Leroy

URL : http://journals.openedition.org/adlfi/8679

ISSN : 2114-0502

Éditeur

Ministère de la culture

Référence électronique

Marc Leroy, "La sidérurgie ancienne en Lorraine », ADLFI. Archéologie de la France - Informations [En ligne], Lorraine, mis en ligne le 01 mars 2001, consulté le 03 mai 2019. URL : http:// journals.openedition.org/adlfi/8679

Ce document a été généré automatiquement le 3 mai 2019.

(c) Ministère de la Culture et de la Communication, CNRS 


\title{
La sidérurgie ancienne en Lorraine
}

\author{
Marc Leroy
}

Identifiant de l'opération archéologique : F1354200000060

Date de l'opération : 2001 (PT)

1 Les recherches paléométallurgiques conduites en Lorraine (programme pluridisciplinaire associant le laboratoire d'Archéologie des Métaux/CCSTI du Fer et de la Métallurgie et le laboratoire de Métallurgies et Cultures - UMR 5060) ont pour objectif de définir les conditions et la chronologie du développement de la production sidérurgique, avant la généralisation des procédés modernes dans le courant du XVIII $\mathrm{s}$. Elles ont jusqu'à présent démontré l'utilisation largement préférentielle du minerai oolithique aalénien (la minette) en sidérurgie directe, dès la période romaine, durant tout le Moyen Âge et même encore au début de la période des Temps Modernes.

2 La campagne 2001 de prospections pédestres a porté sur plusieurs espaces géographiques du plateau de Haye, du Grand-Couronné et du Pays-Haut. Si sur le territoire de la commune de Marbache (54), où 30 ha ont été prospectés, et dans le vallon du bois de Saint-Goule à Custines (54), aucun vestige archéologique n'a été détecté, en revanche deux nouveaux amas de scories et un indice de ferrier ont été découverts, en forêt communale d'Anderny (54), dans un étroit vallon en forêt de Mance (54), sur le flanc du mont Saint-Jean à Moivrons (54) et sur celui du bois de Butte à Audun-le-Tiche (57).

À Anderny, l'amas de scories est composé de deux petits monticules accolés qui occupent une surface de $25 \mathrm{mx} 12 \mathrm{~m}$, mais n'excèdent pas $1,50 \mathrm{~m}$ de hauteur. Les scories cordées caractéristiques de la réduction en bas-fourneaux sont associées à de petits fragments de minerai oolithique (minette). Le minerai de fer provient donc de secteurs d'exploitation situés plus à l'est, puisque les affleurements les plus proches sont localisés dans la vallée du Conroy, à au moins $12 \mathrm{~km}$ de distance. Les deux excavations situées à moins d'une centaine de mètres du ferrier, et creusées dans les «Marnes de Gravelottes » ont donc une toute autre destination qui n'est pas nécessairement liée à l'activité sidérurgique. Le ferrier n'a livré aucun élément de datation. 
L'emplacement de ferrier localisé à l'extrémité nord-est du territoire communal de Mance n'est pas non plus situé en contrebas d'un secteur d'affleurement du minerai oolithique. Dans ce cas aussi, si le minerai utilisé est la minette, il provient de la vallée du Conroy située à quelques kilomètres plus à l'est. Le ferrier ne présente aucune élévation visible, mais il a vraisemblablement été recouvert par les alluvions du ruisseau en bordure duquel il est implanté, au creux d'une étroite vallée fortement encaissée dans le plateau calcaire. Tous les versants environnants (Bois d'Avril) livrent des dizaines d'emplacements d'anciennes charbonnières, dont la relation avec les amas de scories du secteur ne peut être démontrée.

Sur les flancs du mont Saint-Jean, un nouvel indice d'emplacement de ferrier (commune de Moivrons) s'ajoute à ceux trouvés précédemment en 1999 et 2000. Contrairement à l'amas de scories étalé d'époque romaine identifié dans l'ensellement entre mont SaintJean et mont Toulon, ces zones n'ont livré qu'une faible densité de scories, sur une surface restreinte mais néanmoins significative. Il pourrait d'agir d'emplacements de ferrier totalement démantelés par les travaux agricoles, mais peut-être aussi, à l'inverse, le signe d'un recouvrement presque total par les colluviumde versant.

6 Une reconnaissance fine et des sondages à la tarière ont permis de préciser la nature de la zone de scories repérée il y a quelques années sur le flanc du plateau du bois de Butte qui domine la ville d'Audun-le-Tiche. Une couche épaisse de scories et de parois de fours est bien présente sous la surface, vraisemblablement recouverte par les éboulis de pente. De petits tessons attribuables à la période gallo-romaine confirment les observations précédentes. Des analyses chimiques de scories ont montré que le minerai utilisé était, cette fois-ci, du fer fort, dont des gisements étaient connus au XIX ${ }^{e}$ s. sur le sommet du plateau.

7 Sur le plateau de Haye, dans le vallon des Cinq Fontaines à Villers-lès-Nancy, les dégagements en cours des souches d'arbres tombés lors de la tempête de décembre 1999 ont permis de préciser la superficie couverte par les vestiges miniers anciens déjà repérés. Celle-ci apparaît désormais considérable : $700 \mathrm{~m}$ de longueur pour 10 ha environ. Des centaines de minières creusées dans un affleurement de la couche de minerai oolithique encadrent un ferrier non daté, mais qui pourrait être en relation avec l'abbaye cistercienne de Clairlieu toute proche. Les prospections ont également permis de repérer, entre certaines excavations, des traces d'anciens murets de pierres associés à des fragments de tegulae ainsi qu'un lambeau de couche d'occupation d'époque romaine. Ces observations, tout en apportant des informations complémentaires sur les parcellaires antiques fossilisés reconnus en forêt de Haye, confirment le développement postérieurement à l'époque romaine de l'activité minière.

Une opération de prospection géophysique (mesures magnétiques) a été réalisée sur l'amas de scories des Noires Terres à Messein, afin de préciser l'extension exacte du ferrier et de tester l'apport de cette méthode à la reconnaissance de ce type de site (moyens de l'UMR 5060-laboratoire de Métallurgies et Cultures-Belfort et de l'UMR 7619 - université de Paris VI, N. Florsch). Des sondages archéologiques devaient en effet être réalisés ultérieurement en raison d'un projet d'aménagement pesant sur cette zone. Ceux-ci ont, du reste, été effectués à la fin de l'été 2001. Ils ont permis de vérifier la bonne correspondance entre les zones d'anomalies magnétiques et les amas de scories métallurgiques découverts. En revanche, la prospection magnétique n'a pas permis de préciser plus finement la localisation des structures de production (bas-fourneaux notamment). 
9 Les études de laboratoire ont porté sur l'examen de lots de scories provenant de trois opérations d'archéologie préventive réalisées en 1999 (Imling, voir Bilan scientifique régional 1999:73) et 2000 (Escherange-Molvange, voir Bilan scientifique régional 2000:74), et de prospections en surface d'un habitat d'époque romaine (Sorbey-55), d'une zone d'occupation médiévale (Rarécourt-55) et d'un site de hauteur de l'âge du fer (Varrinchâtel-88). Si pour plusieurs d'entre eux, il s'agit clairement de déchets d'activité de forge, à Molvange, dans un contexte d'occupation d'époque mérovingienne, les scories observées se rapportent à une activité de réduction.

10 LEROY Marc

INDEX

operation Prospection thématique (PRT)

Index géographique : Lorraine

Index chronologique : âge du Fer, Empire romain, ép. contemporaine, Moyen Âge*, haut Moyen

Âge, Moyen Âge, Temps Modernes

Thèmes : abbaye, bas-fourneau, exploitation, fer, ferrier, four, habitat, métallurgie, minerai, prospection géophysique, scories, sidérurgie, site de hauteur, tuile

\section{AUTEUR}

MARC LEROY

SDA 